\title{
Meconium Aspiration Syndrome: Possible Pathophysiological Mechanisms and Future Potential Therapies
}

\author{
Paal Helge Haakonsen Lindenskov ${ }^{b}$ Albert Castellheim ${ }^{a} \quad$ Ola Didrik Saugstad $^{d}$ \\ Tom Eirik Mollnesc, e-h \\ aDepartment of Paediatric Anaesthesiology and Intensive Care, Queen Silvia Children's Hospital, Sahlgrenska \\ University Hospital, Gothenburg, Sweden; Departments of ${ }^{\mathrm{b}}$ Anaesthesiology and $\mathrm{C}$ Immunology, Oslo University \\ Hospital, Rikshospitalet, dDepartment of Paediatric Research, Oslo University Hospital, Rikshospitalet, University

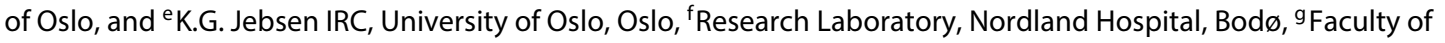 \\ Health Sciences, K.G. Jebsen TREC, University of Tromsø, Tromsø, and h Centre of Molecular Inflammation Research, \\ Norwegian University of Science and Technology, Trondheim, Norway
}

\section{Key Words}

Meconium aspiration syndrome · Inflammation .

Complement system

\begin{abstract}
Does meconium cause meconium aspiration syndrome (MAS) or is meconium discharge only a marker of fetal hypoxia? This dispute has lasted for centuries, but since the 1960s, detrimental effects of meconium itself on the lungs have been demonstrated in animal experiments. In clinical MAS, persistent pulmonary hypertension of the newborn is the leading cause of death in MAS. Regarding the complex chemical composition of meconium, it is difficult to identify a single agent responsible for the pathophysiology. However, considering that meconium is stored in the intestines, partly unexposed to the immune system, aspirated meconium could be recognized as 'danger', representing damaged self. The common denominator in the pathophysiology could therefore be activation of innate immunity. Thus, a bulk of evidence implies that meconium is a potent activator of inflammatory mediators, including cytokines, complement, prostaglandins and reactive oxygen species. We hy-
\end{abstract}

pothesize that the two main recognition systems of innate immunity, the Toll-like receptors and the complement system, recognize meconium as 'danger', which leads not only to lung dysfunction but also to a systemic inflammatory response. This might have therapeutic implications in the future.

(c) 2015 S. Karger AG, Basel

\section{Meconium Aspiration Syndrome}

Meconium aspiration syndrome (MAS) has been defined by clinical criteria: (1) respiratory distress (tachypnoea, retractions or grunting) in a neonate born through meconium-stained amniotic fluid (MSAF); (2) a need for supplemental oxygen to maintain oxygen saturation of haemoglobin $\left(\mathrm{SaO}_{2}\right)$ at $92 \%$ or more; (3) oxygen requirements starting during the first $2 \mathrm{~h}$ of life and lasting for at least $12 \mathrm{~h}$ and (4) absence of congenital malformations of the airway, lung or heart [1].

The incidence of MSAF in all births was in the 1990s estimated to be within a wide range from 7 to $22 \%$ as reviewed by Katz and Bowes [2], but the incidence of MSAF 
in 2000-2007 in 132,884 French newborns (37-43 weeks gestational age) was $8 \%$, the incidence of MAS was $0.2 \%$ and the incidence of severe MAS with a need for respiratory support was $0.067 \%$ [3].

Meconium consists of numerous substances of host origin mainly derived from the digestive tract, including salivary, gastric, pancreatic and intestinal juices, mucus, bile, bile acids, cellular debris, lanugo hairs, fetal wax and blood. Notably, since meconium is located 'extracorporeally', like the whole content of the gastrointestinal tract, its constituents are hidden and normally not recognized by the fetal immune system. Normally, meconium is sterile as the colon is inoculated with bacteria after delivery. This is important with respect to the view of meconium as a potential danger to the fetus, containing innumerable potentially endogenous signals that can be recognized as 'damaged self by the immune system.

\section{Pathophysiology of MAS - Still to Be Resolved}

Despite substantial publications on MAS, the pathophysiology of MAS has still been incompletely clarified. An explanation may be the complex composition of meconium, which has made it difficult to identify a single agent responsible for pathophysiology. Nevertheless, MAS may be regarded as a multifactorial disease with various pathophysiologic processes. Traditionally, there is an approach including mechanical blockade of the airways, inactivation of surfactant and pulmonary arterial hypertension. Our main focus here, however, will be on inflammation.

\section{Inflammation}

To cope with injuries anywhere in the body, the immune system has a mobile force of cells maintaining intercellular communication through cell-to-cell contact or by the secretion of signal molecules. The main task of inflammation is repair, but clearly, its devastating potential may cause significant tissue damage locally as well as more widespread in case the process of walling-off, killing and eliminating the microbes or other tissue-damaging factors fails. Even though it is still debated to what extent meconium per se compared to hypoxia causes MAS, the bulk of available evidence implies that meconium is a potent activator of inflammatory cascades. In particular, evidence suggests that several of the various chemical components constituting meconium may be toxic and induce inflammation and apoptosis. Taken together, the pathophysiological processes in MAS are multifactorial and in- completely understood, which may explain the experience-based nature of the clinical therapy. Recently, the state of the art in the treatment of MAS was reviewed by Wiswell [4].

\section{Inflammation in MAS - Lessons Learned from Experimental Studies}

In experimental MAS, the focus has almost without exception been on mechanisms of lung damage $[5,6]$, but recently, several authors have focused on a possible systemic inflammation in MAS [7, 8], supported by experimental data. The assumed chemical pneumonitis caused by meconium was first documented in 1978 when leukocyte infiltration was demonstrated in rabbit lungs after meconium aspiration [9]. The altered internal response pattern of the defence systems in such animal models should be taken into consideration before drawing any conclusions on the pathophysiology in clinical MAS. Apoptosis, cellular infiltration, increased airway responsiveness or increased cytokine concentrations in bronchoalveolar lavage of animal lungs instilled with meconium have later been demonstrated in numerous studies $[10,11]$. Increased biosynthesis of prostaglandins and nitric oxide is shown in rabbit lungs after meconium aspiration [12], but in human neonatal lungs, the impact of nitric oxide on inflammation is unsettled.

Despite an increasing focus on lung inflammation in MAS and increasing documentation on possible effector molecules in these complex processes, the cellular mechanisms initiating the inflammatory reactions remain to be clarified. Furthermore, both clinical and experimental data support the notion that MAS, in addition, should be interpreted in a context of systemic inflammation paralleling the inflammation in neonatal sepsis, and C-reactive protein (CRP) as an inflammatory mediator has been shown in non-infectious newborns with MAS [13]. The inflammatory network is complex, and the different branches are intensively cross-talking. The mediators which have been most studied in experimental MAS are the cytokines, the complement system, reactive oxygen species (ROS), nitric oxide, arachidonic acid metabolites and transcription factors.

\section{Cytokines}

Cytokines are signalling molecules for intercellular communication inducing growth, differentiation, chemotaxis, activation and enhanced cytotoxicity on target 
cells. The chemokines, e.g. interleukin 8 (IL-8), comprise a separate group of cytokines primarily involved in chemoattraction of leukocytes to the site of tissue damage. Cytokines are largely produced in response to pattern recognition by the Toll-like receptor (TLR) family. In vitro, meconium has been shown to induce neutrophil chemotaxis mediated through IL-8 present in meconium [14]. However, our own data imply a de novo synthesis of IL-8 (lung lavage fluid) in animal experiments [10]. In MSAF, high levels of tumour necrosis factor (TNF), IL$1 \beta$, IL- 6 and IL- 8 have been detected, all with chemotactic activity on leukocytes [15].

Further, the levels of TNF, IL- $1 \beta$, IL- 6 and IL- 8 have been compared in sterile meconium and meconium contaminated with bacteria, where despite variation among samples the median concentrations did not differ [16]. Thus, meconium that was sterile at birth may be contaminated with nosocomial bacteria at least $72 \mathrm{~h}$ postnatally. The authors speculated that proinflammatory substances in meconium, like haeme, could primarily induce lung inflammation directly and, further, indirectly by inducing cytokine release from alveolar cells. We have demonstrated in vitro the inhibition of meconium-induced cytokine and growth factor release by the inhibition of complement $[17,18]$, underscoring that complement acts upstream to the cytokine network. Furthermore, by incubating human blood with human meconium and observing the release of a large panel of inflammatory mediators, we found a marked inhibition of cytokine release using the TLR4/MD2 inhibitor cyanobacterial product (CyP) and an anti-CD14 monoclonal antibody, suggesting a CD14-dependent TLR4 activation by meconium [19].

It is conceivable that hypoxia due to MAS, ventilatorinduced baro-/volutrauma and oxygen therapy all may trigger inflammation in vivo. High-frequency oscillatory ventilation may be beneficial in clinical MAS complicated by pulmonary interstitial emphysema [20]. Zagariya et al. [21] used an animal model and compared the effects of saline, milk and meconium instillation into the rabbit lungs. They further used an in vitro cell model with hypoxia-, hyperoxia- and meconium-treated cells. Their results give reason to argue against the view that anything else than meconium could cause MAS. Recently, a significant increase in proinflammatory cytokines as well as in anti-inflammatory IL-10 was documented within $6 \mathrm{~h}$ in serum from human neonates suffering from MAS [22]. The theme of cytokine expression and apoptosis in MAS pathophysiology has recently been reviewed by several authors [5-7].

Meconium Aspiration Syndrome

\section{The Complement System}

The complement system is a major humoral defence system of innate immunity closely interacting with the adaptive immune system. The system was named thus by Charles Bordet in 1895 based on his observation that serum with specific antibodies (antiserum) capable of disintegrating bacteria lost this capacity when warmed up but regained lysis when mixed with new serum devoid of specific antibodies. In other words, serum contains heatlabile factor(s) complementing the antibodies. Today's view of complement is that it is far more than just a defence system against microbes, as it participates broadly in tissue homeostasis with clearage of debris and tissue regeneration [23].

In principle, the complement system is activated whenever presented with structures not normally presented to the immune system. These represent exogenous structures like microbes but also endogenous structures exposed after damage, like trauma and ischemiareperfusion injury ('damaged-self). There are three pathways of initial complement activation (recognition pathways): the classical, the lectin and the alternative pathway (fig. 1). The three activation pathways converge at the main component $\mathrm{C} 3$, proceeding further to the terminal pathway, with $\mathrm{C} 5 \mathrm{a}$ and the terminal complement complex as end products. C5a is placed at the top of the list of potentially harmful inflammatory mediators. Previous studies from our group demonstrated that meconium activates neutrophils through C5a in vitro [24]. We later documented that meconium has a potential to activate the initial complement pathways on a broader basis [18].

\section{Other Inflammatory Mediators in MAS}

ROS are inflammatory mediators with a primary function of protecting the host, but with a strong potential to cause harm to the host [25]. Complement is known to induce reactive oxygen, mainly through $\mathrm{C} 5 \mathrm{a}$-mediated leukocyte oxidative burst [26]. We have documented that meconium strongly induced complement-dependent oxidative burst in human neutrophils [24]. Nonetheless, the role of oxidative burst in MAS is controversial [27, 28].

The arachidonic acid pathway is an important proinflammatory mediator system. It starts when phospholipase $A_{2}$ releases arachidonic acid from phospholipids in the cell membrane. Human meconium has been shown to contain phospholipase $A_{2}$ and is thus capable of directly damaging alveolar cells [29]. 


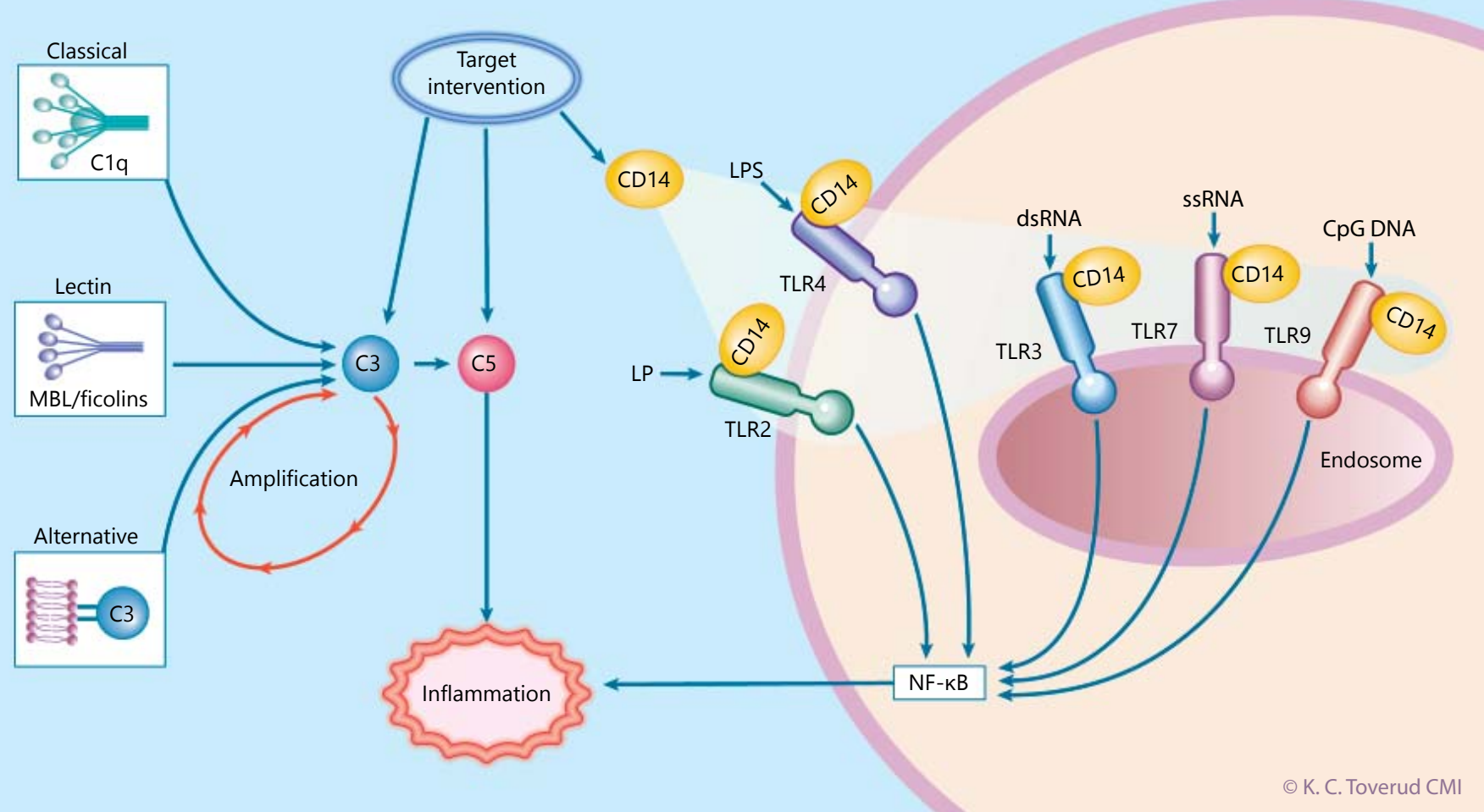

Fig. 1. A novel approach for inhibition of inflammation achieved by targeting the key complement molecules C3 or C5 and the CD14 molecule of the TLR family. First published by Barratt-Due et al. [35]. Printed with permission from Kari C. Toverud, Oslo.

The nuclear factor $\kappa \mathrm{B}(\mathrm{NF}-\kappa \mathrm{B})$ family is an example of gene-regulatory proteins with binding sites in the genes of proinflammatory cytokines like TNF, IL-6, IL-8, adhesion molecules and other immune modulators (e.g. cyclooxygenase-2 and nitric oxide synthase) [30]. Meconium has been shown to activate expression of NF- $\kappa \mathrm{B}$ in rat alveolar macrophages.

\section{MAS Today and in the Future - Time for Reflection and New Concepts?}

Pattern Recognition and Danger Sensing by the Innate Immune System

The first line of defence is the recognition phase which is exerted by the innate immune system already present at birth and often called natural immunity. It responds within minutes with low specificity and no memory in an attempt to kill and eliminate microbes. The major cell types of this system are the phagocytes (neutrophils and monocytes/macrophages), while the main effector molecules include cytokines, complement and acute phase proteins contributing to the inflammatory reaction. The inflammatory reaction includes a complex network of molecules which can be divided into inducers, sensors, mediators, translators, effectors and regulators [31].

The current view of the function of the innate immune system is to recognize 'danger'. Danger in this sense means structures not normally exposed to the innate immune system. Such structures are recognized by the socalled pattern recognition receptors (PRR) [32]. These are present on cell membranes typically as TLRs (fig. 1) or, in the fluid phase, as complement components. PRRs recognize both exogenous ligands such as those present on microbes, called 'pathogen-associated molecular patterns' (PAMP), or endogenous ligands ('alarmins') exposed when tissue is damaged, the so-called 'damage-associated molecular patterns' (DAMP). The latter, 'damaged self, leads to sterile inflammation, for instance when a cell undergoes necrosis or when the endothelium is damaged by an ischemia-reperfusion process. In contrast, cell death by apoptosis does not release endogenous ligands recognized by PRRs and, therefore, does not induce inflammation. 
TLRs and complement are the two main danger recognition systems (fig. 1). Activation of these systems initiates the secondary inflammatory response, that is the activation of leukocytes and the release of cytokines, ROS, expression of adhesion molecules, etc. Thus, it is plausible that inhibition of these upstream systems (TLR and complement) would attenuate the subsequent inflammatory response. We have shown that this is the case for inflammation caused by Gram-negative bacteria $[33,34]$ and have put forward the hypothesis of a combined inhibition of CD14 (being a co-receptor for several TLRs) and of complement as a treatment regimen in conditions characterized by a systemic inflammatory response $[35,36]$. This might be in accordance with Romero et al. [37] who identified Gram-negative rods as the most common isolates in the amniotic fluid of patients with MSAF. This finding, however, should not be over-interpreted since most infants with MAS do not have a super-added bacterial infection. The same group demonstrated elevated IL- 6 concentration in MSAF as a sign of intra-amniotic inflammation.

\section{The Danger of Meconium}

Of note, normal meconium is sterile and consists of selfstructures only. However, being stored in the intestinal tract, these are hidden for the immune system. There are numerous endogenous danger ligands in meconium which is composed of cell debris. These danger ligands have the potential to activate the innate immune system when the airways are exposed to them. Thus, we started to investigate the effect of meconium on the human innate immune system in vitro and in a piglet model of MAS in vivo. The meconium we used was obtained sterile and documented to be free from bacteria and endotoxin $(<20$ pg lipopolysaccharide/mg meconium). The effects observed could, therefore, only be explained by endogenous ligands.

We first showed that meconium was a potent activator of both human and pig complement in vitro [38] and, additionally, that the degree of complement activation reflected the systemic inflammatory response [39] and disease activity [40] in MAS in piglets in vivo. Furthermore, the meconium-induced neutrophil activation, as measured by surface activation markers and oxidative burst, was shown to be induced by the complement anaphylatoxin C5a [24]. Our further studies revealed inflammation attenuation mechanisms when a $\mathrm{C} 1$ inhibitor was used [18]. Interesting enough regarding therapy, we have observed in the piglet model of MAS that pulmonary lavage in fact increased the systemic complement activation compared to untreated animals, suggesting that lavage may increase the systemic inflammation in MAS.
Based on the abovementioned studies, we have reviewed the effect of meconium on complement and its role as a potent initiator of systemic inflammation [8].

These studies, supporting meconium as a potent activator of complement, prompted us to investigate whether it would also activate the TLR system. In a subsequent study, we demonstrated that CyP, a potent TLR4 antagonist, markedly inhibited meconium-induced cytokines in human whole blood, which was CD14 dependent [19]. Since CD14 is a co-receptor for several of the TLRs [19], we continued our in vitro studies by combining a neutralizing anti-CD14 antibody with complement inhibition. Notably, this combination virtually abolished all inflammatory responses induced by meconium [17]. The results were quite similar to what we had observed when activating whole blood with Gram-negative bacteria [33]. These studies supported the view that recognition of danger and initiation of inflammation by the innate immune system is similar regardless of ligands being endogenous or exogenous. Collectively, our data on meconium as a potent activator of both complement and the TLRs, reflected by increased complement activation products and a series of cytokines both in vitro and in piglet experiments in vivo, support our hypothesis, and we intend to test the effect of the combined complement and CD14 inhibitory regimen, as illustrated in figure 1 , in experimental MAS. In case this regimen works in experimental MAS, it should be tested in clinical trials in the future.

\section{Concluding Remarks}

As emphasized in this review, both the aetiology and pathophysiology of MAS are complex, implying that the therapeutic approaches still are directed towards symptom treatment and life-supporting emergency medicine, with limited improvements of prognosis over the last years. In this respect, MAS is quite similar to sepsis, where there is an urgent need for understanding the pathophysiology in order to improve therapy and prognosis [35]. In conclusion, we claim that the present knowledge on MAS suggests that meconium is a danger signal for the innate immune system and a potent activator of both complement and TLRs. Accordingly, we urge future experimental MAS therapy studies targeting PRRs recognizing meconium. The combined inhibition of complement and CD14 should be regarded as a possible therapeutic regimen in MAS.

\section{Disclosure Statement}

The authors declare that they have no conflicts of interest. 


\section{References}

$>1$ Vain NE, Szyld EG, Prudent LM, Wiswell TE, 16 De Beaufort AJ, Bakker AC, van Tol MJ, Aguilar AM, Vivas NI: Oropharyngeal and nasopharyngeal suctioning of meconiumstained neonates before delivery of their shoulders: multicentre, randomised controlled trial. Lancet 2004;364:597-602.

$>2$ Katz VL, Bowes WA Jr: Meconium aspiration syndrome: reflections on a murky subject. Am J Obstet Gynecol 1992;166:171-183.

$>3$ Fischer C, Rybakowski C, Ferdynus C, Sagot P, Gouyon JB: A population-based study of meconium aspiration syndrome in neonates born between 37 and 43 weeks of gestation. Int J Pediatr 2012;2012:321545.

-4 Wiswell TE: Meconium aspiration syndrome; in Donn SM, Sinha SK (eds): Manual of Neonatal Respiratory Care. New York, Springer, 2012, pp 555-564.

$>5$ Van Ierland Y, de Beaufort AJ: Why does meconium cause meconium aspiration syndrome? Current concepts of MAS pathophysiology. Early Hum Dev 2009;85:617-620.

$\checkmark 6$ Vidyasagar D, Zagariya A: Studies of meconium-induced lung injury: inflammatory cytokine expression and apoptosis. J Perinatol 2008;28(suppl 3):S102-S107.

7 Kaapa PO: Meconium aspiration syndrome (MAS) - where do we go? Research perspectives. Early Hum Dev 2009;85:627-629.

$>8$ Mollnes TE, Castellheim A, Lindenskov PH, Salvesen B, Saugstad OD: The role of complement in meconium aspiration syndrome. J Perinatol 2008;28(suppl 3):S116-S119.

$>9$ Tyler DC, Murphy J, Cheney FW: Mechanical and chemical damage to lung tissue caused by meconium aspiration. Pediatrics 1978;62: 454-459.

$>10$ Lindenskov PH, Castellheim A, Aamodt G, Saugstad OD: Meconium induced IL-8 production and intratracheal albumin alleviated lung injury in newborn pigs. Pediatr Res 2005; 57:371-377.

-11 Zagariya A, Bhat R, Navale S, Vidyasagar D: Cytokine expression in meconium-induced lungs. Indian J Pediatr 2004;71:195-201.

$>12$ Kytola J, Kaapa P, Uotila P: Meconium aspiration stimulates cyclooxygenase- 2 and nitric oxide synthase- 2 expression in rat lungs. Pediatr Res 2003;53:731-736.

13 Hofer N, Muller W, Resch B: Non-infectious conditions and gestational age influence Creactive protein values in newborns during the first 3 days of life. Clin Chem Lab Med 2011;49:297-302.

14 De Beaufort AJ, Pelikan DM, Elferink JG, Berger HM: Effect of interleukin 8 in meconium on in-vitro neutrophil chemotaxis. Lancet 1998;352:102-105.

15 Yamada T, Minakami H, Matsubara S, Yatsuda T, Kohmura Y, Sato I: Meconiumstained amniotic fluid exhibits chemotactic activity for polymorphonuclear leukocytes in vitro. J Reprod Immunol 2000;46:21-30. Poorthuis BJ, Schrama AJ, Berger HM: Meconium is a source of pro-inflammatory substances and can induce cytokine production in cultured A549 epithelial cells. Pediatr Res 2003;54:491-495.

17 Salvesen B, Fung M, Saugstad OD, Mollnes TE: Role of complement and CD14 in meconium-induced cytokine formation. Pediatrics 2008;121:e496-e505.

18 Salvesen B, Nielsen EW, Harboe M, Saugstad OD, Mollnes TE: Mechanisms of complement activation and effects of C1-inhibitor on the meconium-induced inflammatory reaction in human cord blood. Mol Immunol 2009;46:688-694.

19 Salvesen B, Stenvik J, Rossetti C, Saugstad OD, Espevik T, Mollnes TE: Meconium-induced release of cytokines is mediated by the TRL4/MD-2 complex in a CD14-dependent manner. Mol Immunol 2010;47:1226-1234.

20 Squires KA, De Paoli AG, Williams C, Dargaville PA: High-frequency oscillatory ventilation with low oscillatory frequency in pulmonary interstitial emphysema. Neonatology 2013;104:243-249.

21 Zagariya A, Sierzputovska M, Navale S, Vidyasagar D: Role of meconium and hypoxia in meconium aspiration-induced lung injury in neonatal rabbits. Mediators Inflamm 2010;2010:204831.

22 Okazaki K, Kondo M, Kato M, Kakinuma R, Nishida A, Noda M, Taniguchi K, Kimura H: Serum cytokine and chemokine profiles in neonates with meconium aspiration syndrome. Pediatrics 2008;121:e748-e753.

$>23$ Ricklin D, Hajishengallis G, Yang K, Lambris JD: Complement: a key system for immune surveillance and homeostasis. Nat Immunol 2010;11:785-797.

24 Castellheim A, Pharo A, Fung M, Saugstad OD, Mollnes TE: Complement C5a is a key mediator of meconium-induced neutrophil activation. Pediatr Res 2005;57:242-247.

25 Bergamini CM, Gambetti S, Dondi A, Cervellati C: Oxygen, reactive oxygen species and tissue damage. Curr Pharm Des 2004;10: 1611-1626.

26 Shingu M, Nonaka S, Nishimukai H, Nobunaga $M$, Kitamura $H$, Tomo-Oka K: Activation of complement in normal serum by hydrogen peroxide and hydrogen peroxide-related oxygen radicals produced by activated neutrophils. Clin Exp Immunol 1992;90:7278.

27 Clark P, Duff P: Inhibition of neutrophil oxidative burst and phagocytosis by meconium. Am J Obstet Gynecol 1995;173:1301-1305.

28 Soukka HR, Ahotupa M, Ruutu M, Kaapa PO: Meconium stimulates neutrophil oxidative burst. Am J Perinatol 2002;19:279-284.
29 Holopainen R, Aho H, Laine J, Peuravuori H, Soukka H, Kaapa P: Human meconium has high phospholipase A2 activity and induces cellular injury and apoptosis in piglet lungs. Pediatr Res 1999;46:626-632.

30 Abraham E: NF-kappaB activation. Crit Care Med 2000;28:N100-N104.

31 Medzhitov R: Origin and physiological roles of inflammation. Nature 2008;454:428-435.

32 Janeway CA Jr, Medzhitov R: Innate immune recognition. Annu Rev Immunol 2002;20: 197-216.

33 Lappegard KT, Christiansen D, Pharo A, Thorgersen EB, Hellerud BC, Lindstad J, Nielsen EW, Bergseth G, Fadnes D, Abrahamsen TG, Hoiby EA, Schejbel L, Garred P, Lambris JD, Harboe M, Mollnes TE: Human genetic deficiencies reveal the roles of complement in the inflammatory network: lessons from nature. Proc Natl Acad Sci U S A 2009; 106:15861-15866.

34 Mollnes TE, Brekke OL, Fung M, Fure H, Christiansen D, Bergseth G, Videm V, Lappegard KT, Kohl J, Lambris JD: Essential role of the C5a receptor in E. Coli-induced oxidative burst and phagocytosis revealed by a novel lepirudin-based human whole blood model of inflammation. Blood 2002;100: 1869-1877.

35 Barratt-Due A, Pischke SE, Brekke OL, Thorgersen EB, Nielsen EW, Espevik T, Huber-Lang M, Mollnes TE: Bride and groom in systemic inflammation - the bells ring for complement and Toll in cooperation. Immunobiology 2012;217:1047-1056.

36 Mollnes TE, Christiansen D, Brekke OL, Espevik T: Hypothesis: combined inhibition of complement and CD14 as treatment regimen to attenuate the inflammatory response. Adv Exp Med Biol 2008;632:253-263.

37 Romero R, Yoon BH, Chaemsaithong P, Cortez J, Park CW, Gonzalez R, Behnke E, Hassan SS, Chaiworapongsa T, Yeo L: Bacteria and endotoxin in meconium-stained amniotic fluid at term: could intra-amniotic infection cause meconium passage? J Matern Fetal Neonatal Med 2014;27:775-788.

-38 Castellheim A, Lindenskov PH, Pharo A, Fung M, Saugstad OD, Mollnes TE: Meconi$\mathrm{um}$ is a potent activator of complement in human serum and in piglets. Pediatr Res 2004; 55:310-318.

39 Castellheim A, Lindenskov PH, Pharo A, Aamodt G, Saugstad OD, Mollnes TE: Meconium aspiration syndrome induces complement-associated systemic inflammatory response in newborn piglets. Scand J Immunol 2005;61:217-225.

40 Lindenskov PH, Castellheim A, Aamodt G, Saugstad OD, Mollnes TE: Complement activation reflects severity of meconium aspiration syndrome in newborn pigs. Pediatr Res 2004;56:810-817. 